\title{
RIP1 maintains DNA integrity and cell proliferation by regulating PGC-1 $\alpha$-mediated mitochondrial oxidative phosphorylation and glycolysis
}

\author{
W Chen ${ }^{1}$, Q Wang ${ }^{1,2}$, L Bai ${ }^{1}$, W Chen ${ }^{1}$, X Wang ${ }^{1,2}$, CS Tellez ${ }^{1}$, S Leng ${ }^{1}$, MT Padilla ${ }^{1}$, T Nyunoya ${ }^{1}$, SA Belinsky ${ }^{1}$ and Y Lin ${ }^{*, 1}$
}

Aerobic glycolysis or the Warburg effect contributes to cancer cell proliferation; however, how this glucose metabolism pathway is precisely regulated remains elusive. Here we show that receptor-interacting protein 1 (RIP1), a cell death and survival signaling factor, regulates mitochondrial oxidative phosphorylation and aerobic glycolysis. Loss of RIP1 in lung cancer cells suppressed peroxisome proliferator-activated receptor $\gamma$ coactivator-1 $\alpha$ (PGC-1 $\alpha$ ) expression, impairing mitochondrial oxidative phosphorylation and accelerating glycolysis, resulting in spontaneous DNA damage and p53-mediated cell proliferation inhibition. Thus, although aerobic glycolysis within a certain range favors cancer cell proliferation, excessive glycolysis causes cytostasis. Our data suggest that maintenance of glycolysis by RIP1 is pivotal to cancer cell energy homeostasis and DNA integrity and may be exploited for use in anticancer therapy.

Cell Death and Differentiation (2014) 21, 1061-1070; doi:10.1038/cdd.2014.25; published online 28 February 2014

A cell's metabolism is optimized for its function and adapts to environmental changes; therefore, it is pivotal to differentiation, proliferation, survival and death. In the presence of ample oxygen, cancer cells prefer glycolysis over mitochondrial respiration for energy supply, which is known as the Warburg effect or aerobic glycolysis. ${ }^{1,2}$ Although aerobic glycolysis was originally thought to complement impaired mitochondrial respiration, recent investigations suggest that it is a driving force in cancer cell transformation and proliferation. ${ }^{3,4}$ In coordination with the tricarboxylic acid cycle and mitochondrial respiration, cancer cells increase glycolysis to support their rapid proliferation. This 'metabolic transformation' in cancer cells not only meets their energy requirements but also provides the building blocks for synthesis of biomass and for maintenance of redox homeostasis. ${ }^{5,6}$ Thus, the metabolic transformation is believed to offer cancer cells a selective growth advantage compared with their normal counterparts and to contribute to drug resistance. Many oncogenes such as c-Myc and Akt, and tumor suppressors such as p53 are involved in the regulation of glycolysis and mitochondrial metabolism, serving as evidence of the necessity for metabolic adaptation in cancer cells. ${ }^{7,8}$ However, how metabolic transformation is precisely regulated needs further elucidation.

Receptor-interacting protein 1 (RIP1) is a serine/threonine kinase with functions in cell proliferation, survival and death. ${ }^{9-11}$ The role of RIP1 in cell survival is achieved mainly through its function as an adaptor in signal pathways, such as
$\mathrm{NF}-\kappa \mathrm{B}$ and PI3K/Akt, that suppress apoptosis. The kinase activity of RIP1 is involved in programmed necrosis or necroptosis. ${ }^{12}$ Although RIP1 can translocate to the mitochondria in certain circumstances and can modulate ADP/ ATP exchange and the production of mitochondrial reactive oxygen species (ROS), ${ }^{13-16}$ whether RIP1 regulates cell energy homeostasis is unknown.

In an attempt to investigate the role of RIP1 in cell proliferation, we uncovered a function for this protein in regulating mitochondrial respiration. RIP1 knockdown resulted in downregulation of $\mathrm{PGC}-1 \alpha$, mitochondrial oxidative phosphorylation (OXPHOS) defect and accelerated glycolysis, leading to spontaneous DNA damage and proliferation suppression. Our results suggest that RIP1 holds glycolysis within a suitable range to maintain cancer cell energy homeostasis and DNA integrity. Thus, intervention in the RIP1-mediated glycolysis pathway may be exploited for use in anticancer therapy.

\section{Results}

Knockdown of RIP1 induces p53-dependent inhibition of lung cancer cell proliferation. Two lentiviral vectors harboring distinct shRNA sequences targeting RIP1 mRNA were used to create stable knockdown lung cancer cells. RIP1 knockdown significantly reduced cell proliferation

\footnotetext{
${ }^{1}$ Molecular Biology and Lung Cancer Program, Lovelace Respiratory Research Institute, 2425 Ridgecrest DR. SE, Albuquerque, NM, USA and ${ }^{2}$ Laboratory of Molecular and Translational Medicine, Key Laboratory of Birth Defects and Related Diseases of Women and Children of Ministry of Education at Sichuan University, Department of Obstetrics and Gynecology, West China Second University Hospital, Sichuan University, Chengdu, China

*Corresponding author: Y Lin, Molecular Biology and Lung Cancer Program, Lovelace Respiratory Research Institute, 2425 Ridgecrest Dr. SE, Albuquerque, NM 87108 , USA. Tel: +1 505348 9645; Fax: +1 505348 4990; E-mail: ylin@Irri.org

Keywords: receptor-interacting protein 1; metabolism; PGC-1 $\alpha$; glycolysis; oxidative phosphorylation; DNA damage

Abbreviations: ATM, ataxia telangiectasia mutated; ATR, ataxia telangiectasia and Rad3 related; BPDE, benzo[a]pyrene diol epoxide; CHK, checkpoint kinase; COX, cytochrome c oxidase; cyt c, cytochrome c; 2-DG, 2-deoxy-D-glucose; GAPDH, glyceraldehyde phosphate dehydrogenase; H2AX, H2A histone family, member X; LDH, lactate dehydrogenase; MDM2, mouse double minute 2 homolog; MnSOD, manganese superoxide dismutase; NAC, $N$-acetyl cysteine; NAD ${ }^{+}$, nicotinamide adenine dinucleotide; NF- $\kappa$ B, nuclear factor-kappa B; PGC-1 $\alpha$, peroxisome proliferator-activated receptor-gamma coactivator $1 \alpha$; PARP, poly (ADP-ribose) polymerase; PI3K, phosphatidylinositide 3-kinase; OXPHOS, oxidative phosphorylation; RIP1, receptor-interacting protein 1; ROS, reactive oxygen species; TNF $\alpha$, tumor necrosis factor $\alpha$ Received 19.6.13; revised 20.1.14; accepted 22.1.14; Edited by G Melino; published online 28.2.14
} 
a
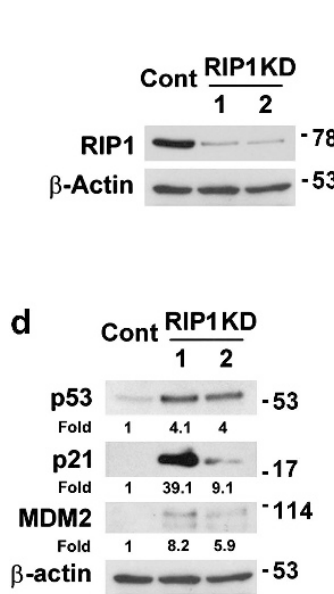

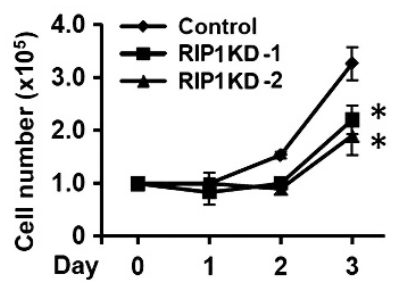

e

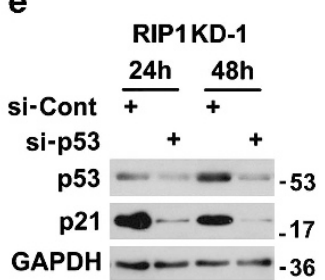

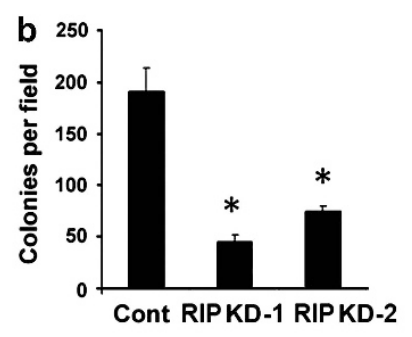
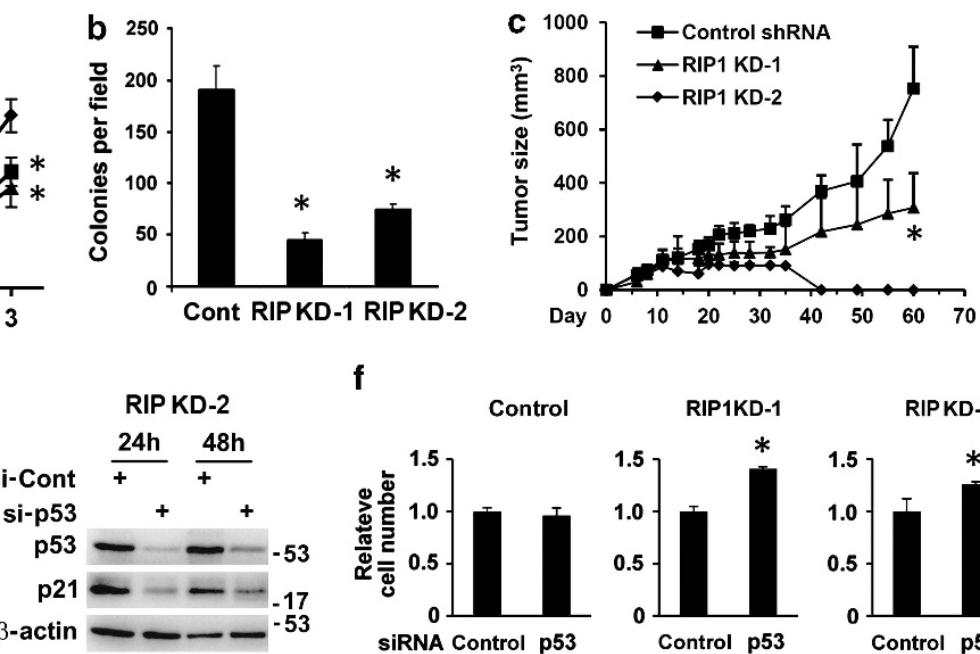

f

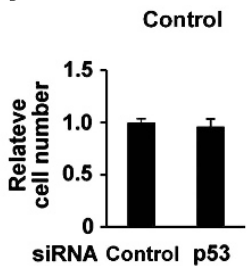

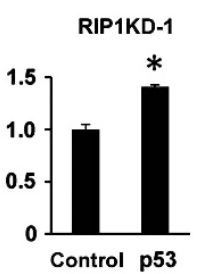

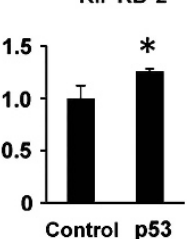

Figure 1 RIP1 knockdown in lung cancer cells results in proliferation inhibition dependent on p53. (a) Proliferation of A549 control (Cont) cells and two clones of RIP1 knockdown (KD) cells. Western blot shows the efficiency of RIP1 knockdown. $\beta$-Actin was probed as a loading control. The values are mean \pm S.D. from triplicate samples. ${ }^{*} P<0.05$ versus control at the identical time point. (b) Growth of $A 549$ control (Cont) cells and RIP1 KD cells in soft agar. The values are mean \pm S.D. from triplicate samples. ${ }^{*} P<0.05$ versus control. (c) Tumor volumes of xenografted A549 control and RIP1 KD cells. The values are mean \pm S.D. $\left(n=6\right.$ for each group). ${ }^{*} P<0.05$ versus control at the identical time points. (d) Protein expression of p53, p21 and MDM2 in A549 control (Cont) and RIP1 KD cells. $\beta$-Actin was detected as a loading control. (e) p21 expression in A549 RIP1 KD cells after siRNA knockdown of p53. GAPDH or $\beta$-actin was used as a loading control. (f) Proliferation of A549 control (Cont) and RIP1 KD cells after p53 knockdown for 4 days. The values are mean \pm S.D. from triplicate samples. ${ }^{*} P<0.05$ versus respective control siRNA transfected cells

(Figure 1a and Supplementary Figure 1a) and colony formation in soft agar when compared with control cells (Figure $1 \mathrm{~b}$ and Supplementary Figure $1 \mathrm{~b}$ ). The growth of tumors derived from control vector-transduced A549 cells subcutaneously injected into nude mice proliferated continuously as in those from parental cells (data not shown), whereas the growth of RIP1 knockdown tumors was retarded, resulting in smaller tumor size or even tumor regression (Figure 1c). These results demonstrate that RIP1 downregulation inhibited the proliferation of lung cancer cells in vitro and in vivo.

RIP1 has been shown to inhibit p53 to promote cell cycle progression. ${ }^{17}$ Indeed, in A549 and $\mathrm{H} 460$ cells that have wild-type p53, RIP1 knockdown elevated the protein expression of p53 together with its targets p21 and MDM2 (Figure 1d and Supplementary Figure 1c). With RIP1 stable knockdown, p21 induction was also seen in $\mathrm{H} 23$ cells with a p53 mutation (M246I) capable of activating p21 expression, ${ }^{18}$ but p21 induction was not observed in p53 inactive mutant (R273L) H2009 and p53 null H1299 cells (Supplementary Figure 1c). Transient knockdown of p53 with siRNA in RIP1deficient cells attenuated p21 expression (Figure 1e and Supplementary Figure 1d). The suppression of p53 boosted the proliferation of RIP1 knockdown cells but not that of control A549 cells (Figure 1f). Further, the inhibition of cell proliferation with RIP1 knockdown was seen in $\mathrm{H} 23$ but not in $\mathrm{H} 2009$ and $\mathrm{H} 1299$ cells (Supplementary Figure 1e). In contrast, the expression of the proapoptotic p53 target gene Bax was unchanged in RIP1 knockdown cells, and no cleavage of PARP, a marker of apoptosis, was observed (Supplementary Figure 2f). These data indicate that increased expression of p53 and p21, without apoptosis, was primarily responsible for the inhibition of proliferation in RIP1 knockdown cells. Because RIP1 is an important component in NF- $\kappa$ B activation induced by distinct stimuli, downregulation of RIP1 may impair activation of this pathway, which in turn may impair cell proliferation. However, this is very unlikely because constitutive NF- $\kappa$ B activity remained unchanged in RIP1 KD cells (Supplementary Figure 1g).

Increased spontaneous DNA damage activates p53 in RIP1 knockdown cells. One common cause for p53 activation is DNA damage. ${ }^{19}$ We observed increased phosphorylation of H2AX (serine 139, $\gamma \mathrm{H} 2 \mathrm{AX}$ ), a widely used marker for DNA double-strand breaks, ${ }^{20,21}$ in RIP1 knockdown lung cancer cells (Figure 2a, Supplementary Figures 2a and $2 b)$. Immunofluorescence showed that the majority of RIP1 knockdown cells were positive for the formation of $\gamma \mathrm{H} 2 \mathrm{AX}$ foci, whereas only a small portion of control cells exhibited $\gamma \mathrm{H} 2 \mathrm{AX}$ foci (Figure 2b). Although ATR target CHK1 only showed mild activation, consistent robust activation of ATM and its downstream target CHK2 was detected (Figure 2a and Supplementary Figure 2a), indicative of elevated DNA double-strand breaks in the RIP1 knockdown cells. Suppression of ATM activation with ATM/ATR inhibitors CGK733 and caffeine $^{22}$ used at low concentrations (relatively specific to ATM), or ATM inhibitor Ku55933, effectively reduced p53 and p21 expression (Figure $2 \mathrm{c}$ and data not shown). These results indicate that DNA damage was responsible for p53 activation in the RIP1 knockdown cells.

DNA damage can result from increased endogenous DNA-damaging agents such as ROS or from decreased DNA repair. $^{23}$ In RIP1 knockdown cells, the ATM-mediated DNA damage response pathway was intact (Figure 2a and supplementary Figure 2a), the basal ROS level was unchanged (Supplementary Figure 2c) and ROS scavenger $\mathrm{N}$-acetyl cysteine (NAC) treatment did not reduce $\gamma \mathrm{H} 2 \mathrm{AX}$ levels (Supplementary Figure 3d), suggesting that increased DNA-damaging agents are probably not the major source of DNA damage in RIP1 knockdown cells. Therefore, we used 
a

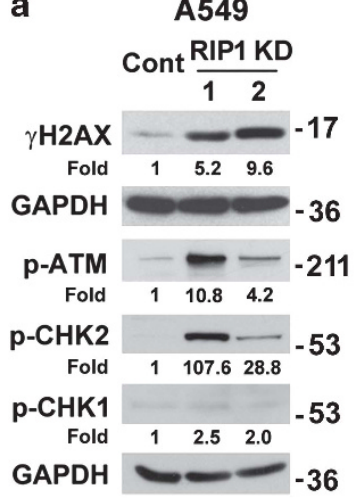

b

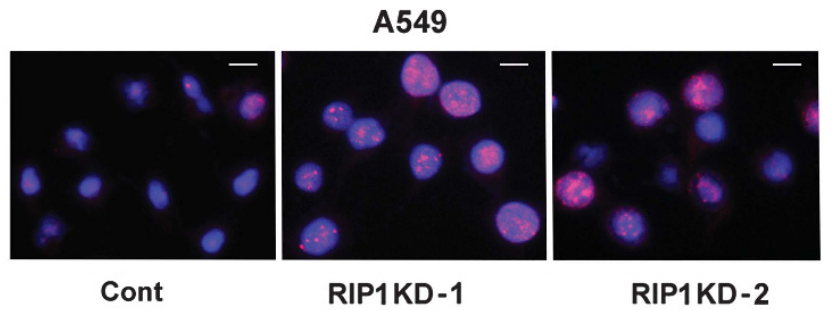

C

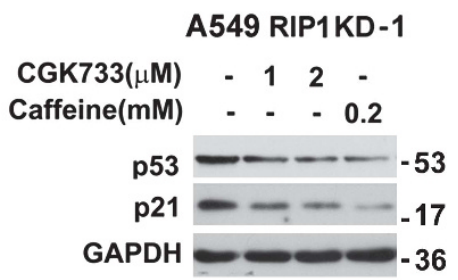

Red: $\gamma$ H2AX Blue: DNA
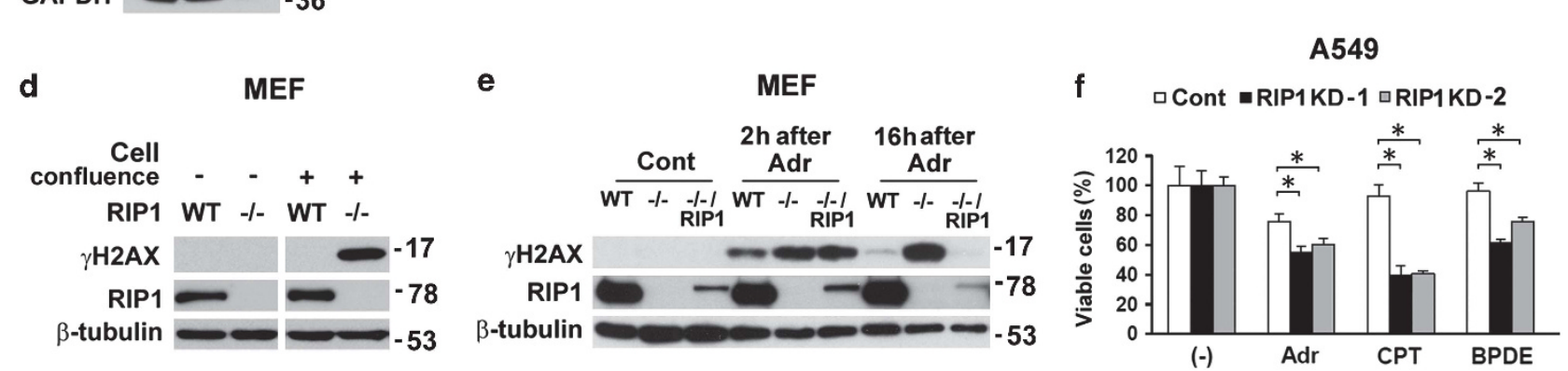

Figure 2 Increased spontaneous DNA damage in RIP1 knockdown cells. (a) A549 control (Cont) and RIP1 KD cells were examined for protein expression of $\gamma$ H2AX, phosphorylation of ATM, CHK1 and CHK2. GAPDH was used as a loading control. (b) A549 control (Cont) and RIP1 KD cells were fixed and $\gamma \mathrm{H} 2 \mathrm{AX}$ foci were detected with immunofluoresence (Red). Nuclei were stained with DAPI (Blue). The scale bar represents $10 \mu \mathrm{m}$. (c) Expression of p53 and p21 in A549 RIP1 KD-1 cells treated with ATM/ATR inhibitors CGK733 or caffeine. GAPDH was used as a loading control. (d) Nonconfluent or confluent wild type (WT) and RIP1 ${ }^{-1}-$ MEFs were examined for $\gamma \mathrm{H} 2 \mathrm{AX}$ and RIP1 expression with western blot. $\beta$-Tubulin was probed as a loading control. (e) Nonconfluent MEFs (WT, RIP1 ${ }^{-1-}$ and RIP1 ${ }^{-1}$ reconstituted with RIP1) were left untreated or treated with adriamycin (Adr) for $1 \mathrm{~h} . \gamma \mathrm{H} 2 \mathrm{AX}$ expression was detected after removal of adriamycin at indicated time points. $\beta$-Tubulin was probed as a loading control. (f) A549 control (Cont) and RIP1 KD cell survival after treatment with adriamycin, camptothecin or BPDE. The values are mean \pm S.D. from triplicate samples. ${ }^{*} P<0.05$

RIP1 knockout (RIP1-/-) mouse embryonic fibroblasts (MEFs) to investigate whether RIP1 deficiency reduces DNA repair capacity. Interestingly, when MEF cells were nonconfluent, $\gamma \mathrm{H} 2 \mathrm{AX}$ was barely detected in both wild type (WT) and RIP1 ${ }^{-1-}$ MEFs; however, when cells were fully confluent and thus not actively cycling, RIP1 ${ }^{-/-}$but not WT MEFs showed elevated $\gamma \mathrm{H} 2 \mathrm{AX}$ level (Figure $2 \mathrm{~d}$ ). Nonconfluent cells were treated with the topoisomerase II inhibitor adriamycin to induce DNA double-strand breaks and further observed for DNA repair response with detection of $\gamma \mathrm{H} 2 \mathrm{AX}$. The WT cells repaired most DNA damage within $16 \mathrm{~h}$, while $\mathrm{RIP1}{ }^{-1}$ - cells showed minimal removal of DNA breaks. Partial restoration of RIP1 expression in RIP1 ${ }^{-1}$ cells restored DNA repair capacity (Figure $2 \mathrm{e}$ ). This result suggests that a moderate RIP1 expression level in MEFs is sufficient to maintain DNA repair capacity, which is similar to the requirement for RIP1 expression in basal (Supplementary Figure $1 \mathrm{~g}$ ) and TNF $\alpha$ induced NF- $\kappa$ B activation. ${ }^{24}$ The persistent high $\gamma \mathrm{H} 2 \mathrm{AX}$ levels in RIP1 ${ }^{-1-}$ cells were not due to cell death (Supplementary Figure 2e). In concert with these findings in MEFs, RIP1 knockdown rendered cells more vulnerable to a variety of DNA double-strand break inducers including anticancer agents, adriamycin, camptothecin, and the cigarette smoke carcinogen benzo[a]pyrene diol epoxide (BPDE) (Figure $2 f$ and Supplementary Figure 2f). These data imply that downregulation of RIP1 impaired DNA repair capacity, which resulted in increased spontaneous DNA damage.
Excessive glycolysis suppresses DNA repair in RIP1 knockdown cells. Despite that RIP1 knockdown cells proliferated more slowly than control cells, we consistently observed that acidification of the culture medium with knockdown cells occurred more quickly, an indication of accelerated mitochondrial metabolism that produces $\mathrm{CO}_{2}$ or enhanced glycolysis that releases lactate. Although both A549 and $\mathrm{H} 460$ are glycolytic cells, ${ }^{25}$ there was a marked increase in lactate release in media after RIP1 downregulation (Figure $3 a$ and Supplementary Figure $3 a$ ). Furthermore, RIP1 knockdown cells had significantly increased lactate dehydrogenase (LDH) activity (Figure $3 b$ and Supplementary Figure 3a) and glucose consumption (Figure $3 \mathrm{c}$ and Supplementary Figure 3a). The RIP1 knockdown cells maintained higher ATP levels compared with control cells (Figure 3d), suggesting that the reduced proliferation was not caused by an energy shortage. In addition, increased LDH activity was also detected in RIP1 knockdown H1299 and RIP1 ${ }^{-1-}$ MEF cells (Supplementary Figure $3 \mathrm{~b})$. As expected, during a brief interval $(30 \mathrm{~h})$ treatment, the viability of RIP1 knockdown cells was more sensitive to extensive glycolysis inhibition with 2-deoxy-Dglucose (2-DG) or oxamate (Figure 3e, Supplementary Figures $3 c$ and $3 d$ ), which would cause an energy crisis. Intriguingly, with longer interval treatment (4 days), mild suppression of glycolysis stimulated proliferation in RIP1 knockdown A549 cells but suppressed proliferation in control 

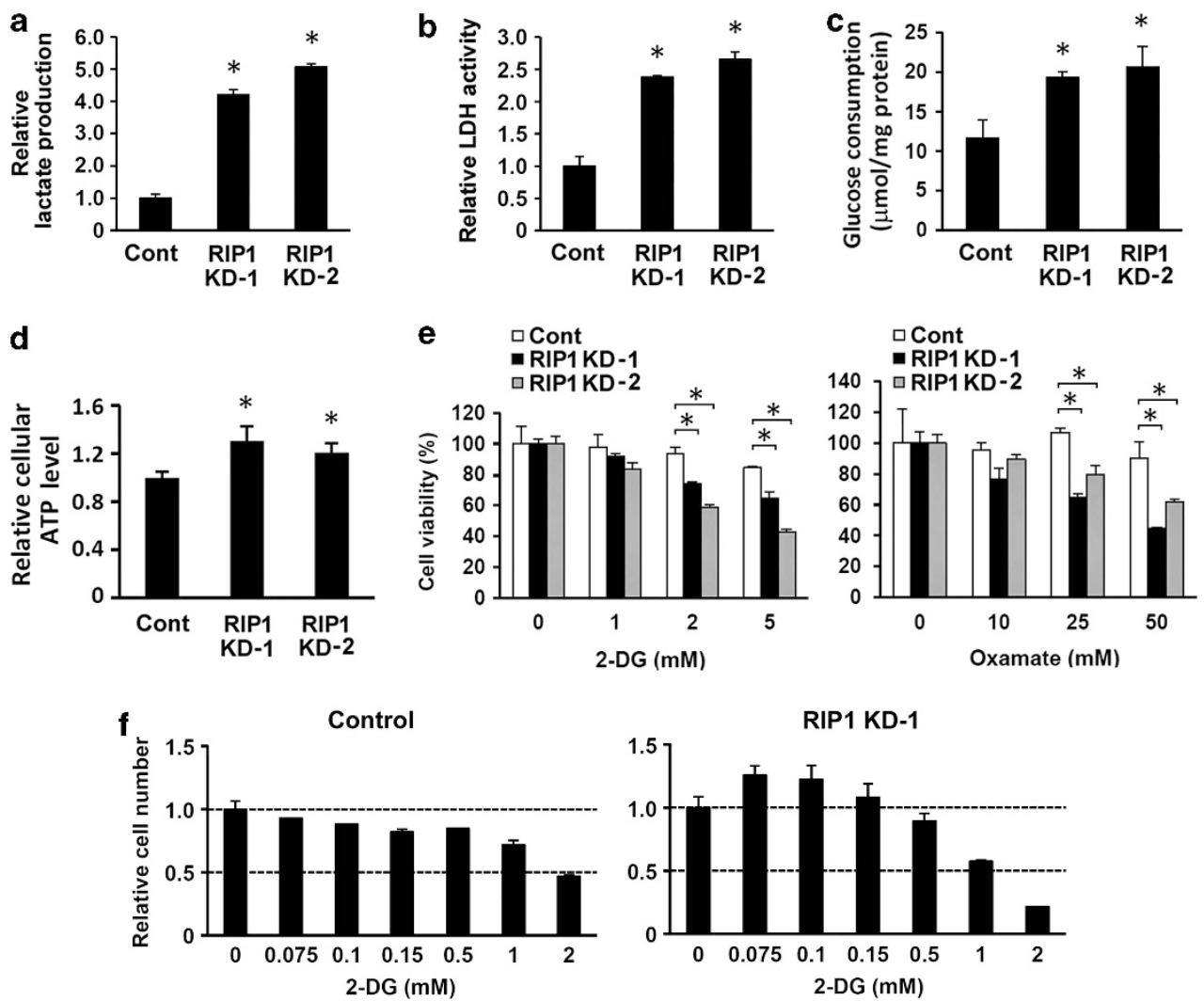

Figure 3 Enhanced glycolysis in RIP1 knockdown cells. (a, b, c and d) Lactate production (a), LDH activity (b), glucose consumption (c) and ATP level (d) in A549 control (Cont) and RIP1 KD cells. The values are mean \pm S.D. from triplicate samples. ${ }^{*} P<0.05$ versus control. (e) Response of A549 control (Cont) and RIP1 KD cells to treatment with various concentrations of glycolysis inhibitors $2-D G$ or oxamate for $30 \mathrm{~h}$. The values are mean \pm S.D. from triplicate samples. ${ }^{*} P<0.05$. (f) Proliferation of $A 549$ control or RIP1 KD-1 cells treated with various concentrations of 2-DG for 4 days. The values are mean \pm S.D. from triplicate samples

cells (Figure $3 f$ and Supplementary Figure $3 e$ and $3 f)$. These results suggest that RIP1 knockdown in glycolytic lung cancer cells accelerates glycolysis (excessive glycolysis), leading to suppression of proliferation.

To determine whether excessive glycolysis elicits spontaneous DNA damage, RIP1 knockdown cells were treated with low concentrations of 2-DG and oxamate to partially suppress glycolysis. Both inhibitors reduced the activation of ATM, CHK2 and $\gamma$ H2AX in RIP1 knockdown cells (Figure 4a and Supplementary Figures $4 a$ and $4 b$ ), indicating that excessive glycolysis contributes to DNA damage and activates the DNA damage response. Note that the very low concentrations of inhibitors that stimulated RIP1 knockdown cell growth also alleviated DNA damage (Supplementary Figure 4c).

$\mathrm{NAD}^{+}$is essential for DNA repair, and its deficiency has been shown to induce spontaneous DNA damage. ${ }^{26,27}$ Because glycolysis converts $\mathrm{NAD}^{+}$to $\mathrm{NADH}$, enhanced glycolysis may lead to additional utilization of $\mathrm{NAD}^{+}$that decreases the cellular $\mathrm{NAD}^{+}$pool. ${ }^{28,29}$ Consistent with this notion, there was a $20-40 \%$ reduction of $\mathrm{NAD}^{+}$in RIP1 knockdown cells compared with that in control cells (Figure 4b). Cell fractionation showed that the most severe reduction in $\mathrm{NAD}^{+}$level occurred in the nuclei (Supplementary Figure 4d). RIP ${ }^{-1-}$ MEFs also contained much lower cytosolic NAD ${ }^{+}$compared with that in WT cells (Supplementary Figure $4 \mathrm{e}$ ). To replenish cellular $\mathrm{NAD}^{+}, \mathrm{RIP1}$ knockdown cells were cultured in medium with nicotinamide
(Nam), a precursor of $\mathrm{NAD}^{+}{ }^{26} \mathrm{Nam}$ addition reduced $\gamma \mathrm{H} 2 \mathrm{AX}$ and p21 levels and increased proliferation in RIP1 knockdown cells but did not affect the proliferation of control cells (Figures $4 \mathrm{c}$ and $\mathrm{d}$ ). These data demonstrate that excessive glycolysis leads to decreased cellular $\mathrm{NAD}^{+}$levels, which may partially be responsible for defective DNA repair and proliferation inhibition in RIP1 knockdown cells.

RIP1 regulates PGC-1 $\alpha$ expression. To investigate the mechanism underlying the metabolic shift, a CDNA array analysis was performed and the gene identified with the highest reduction in RIP1 knockdown cells was PGC-1 $\alpha$, an important regulator of mitochondrial biogenesis and cell metabolism. The result was confirmed by RT-PCR and western blot (Figure 5a and Supplementary Figure 5a). In contrast, the expression of PGC-1 $\beta$, another member of the PGC family, was not altered (Figure 5a). In addition, in wild-type A549 cells, severe glucose starvation $(<0.5 \mathrm{mM}$, supplied only by that contained in $10 \%$ fetal bovine serum) induced downregulation of PGC- $1 \alpha$, which was restored with addition of glucose to the level of that found in normal culture medium. RIP1 knockdown suppressed the basal level of PGC- $1 \alpha$ and attenuated restoration of PGC- $1 \alpha$ expression with glucose replenishment (Figure $5 b$ ), suggesting that RIP1 is involved in glucose-induced PGC- $1 \alpha$ expression.

To further confirm that RIP1 regulates PGC- $1 \alpha$ expression, RIP1 (Xp-RIP1) was overexpressed in HEK293 cells together 
a

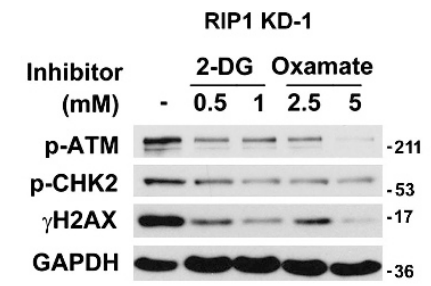

c

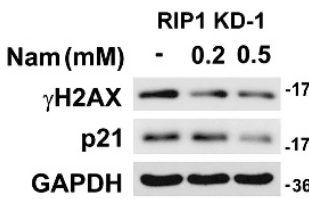

RIP1KD-2

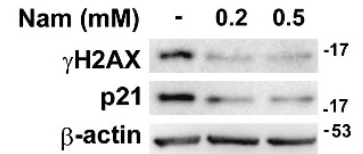

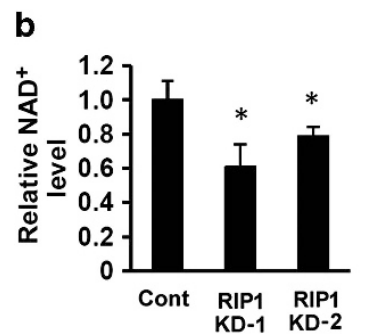
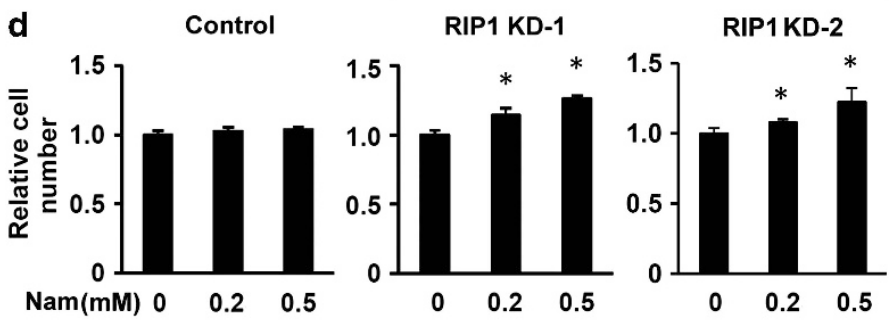

Figure 4 Association of enhanced glycolysis and DNA damage in RIP1 knockdown cells. (a) Phosphorylation of ATM and CHK2 and $\gamma$ H2AX in A549 RIP1 KD-1 cells treated with 2-DG or oxamate for $48 \mathrm{~h}$. GAPDH was probed as a loading control. (b) NAD ${ }^{+}$levels in A549 control and RIP1 knockdown cells. The values are mean \pm S.D. from triplicate samples. ${ }^{*} P<0.05$ versus control. (c) $\gamma \mathrm{H} 2 \mathrm{AX}$ and p21 expression in A549 RIP1 KD cells cultured in medium with $0.2 \mathrm{mM}$ or $0.5 \mathrm{mM}$ nicotinamide for $48 \mathrm{~h}$. GAPDH or $\beta$-actin was probed as a loading control. Note the concentration of nicotinamide in regular RPMI 1640 medium is $0.0082 \mathrm{mM}$. (d) Proliferation of A549 RIP1 KD cells cultured in medium with $0.2 \mathrm{mM}$ or $0.5 \mathrm{mM}$ nicotinamide for 5 days. The values are mean \pm S.D. from triplicate samples. ${ }^{\star} P<0.05$ versus untreated $(0 \mathrm{mM}$ Nam) cells

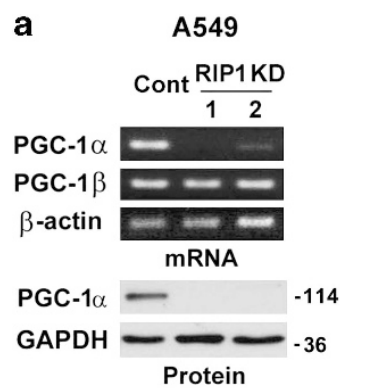

d

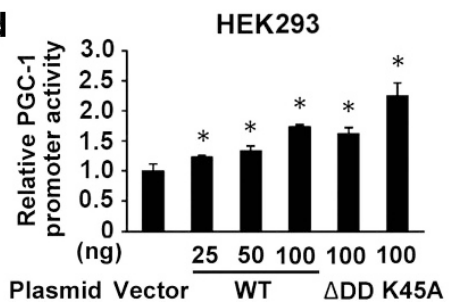

b

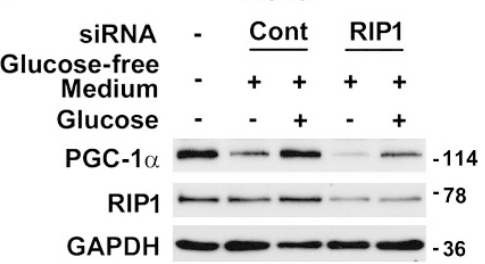

e

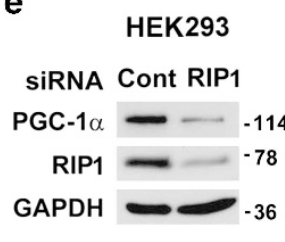

c

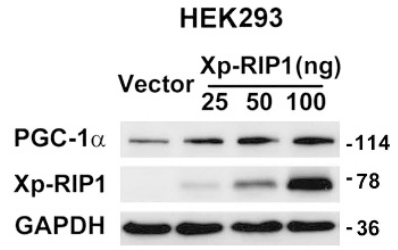

Figure 5 RIP1 regulates PGC-1 $1 \alpha$ expression. (a) PGC- $1 \alpha$ mRNA and protein levels in A549 control (Cont) and RIP1 KD cells. $\beta$-Actin and GAPDH were used as loading controls. (b) PGC-1 $\alpha$ and RIP1 expression in wide-type A549 transfected with control (Cont) or RIP1 siRNA followed by glucose starvation without or with $10 \mathrm{mM}$ glucose supplement. Note the glucose concentration in fresh RPMI 1640 medium is $11 \mathrm{mM}$. GAPDH was probed as a loading control. (c) PGC-1 $\alpha$ expression in HEK293 cells transfected with control vector or Xpress-RIP1 (Xp-RIP1). GAPDH was probed as a loading control. (d) PGC-1 promoter activity in HEK293 cells transfected with control vector, Xp-RIP1 and its death domain deletion $(\triangle \mathrm{DD})$ or kinase death $(\mathrm{K} 45 \mathrm{~A})$ mutants. The values are mean \pm S.D. from triplicate samples. ${ }^{*} P<0.05$ versus vector transfection. (e) PGC-1 expression and promoter activity in HEK293 cells after knockdown of RIP1. GAPDH was used as a loading control. The values are mean \pm S.D. from triplicate samples. ${ }^{*} P<0.05$ versus control

with a luciferase reporter construct with the PGC- $1 \alpha$ promoter. Expression of Xp-RIP1 not only increased luciferase activity, indicative of promoter activation, but also drove endogenous PGC- $1 \alpha$ expression in the cells, in a dose-dependent manner (Figures $5 \mathrm{c}$ and $\mathrm{d}$ and Supplementary Figure $5 \mathrm{~b}$ ). Conversely, knockdown of RIP1 in HEK293 cells reduced the expression of luciferase and endogenous PGC- $1 \alpha$ (Figure $5 \mathrm{e}$ ). Interestingly, neither death domain $(\mathrm{DD})$ deletion $(\triangle \mathrm{DD})$ nor kinase death mutation (K45A) of RIP1 affected the protein to enhance PGC- $1 \alpha$ promoter activity (Figure $5 d$ and
Supplementary Figure $5 b$ ). These results signify that the $\triangle \mathrm{DD}$ and the kinase death mutants of RIP1 cannot operate as dominant negative mutations to block endogenous RIP1 function for PGC1 $\alpha$ expression; furthermore, the DD and kinase activity of RIP1 are not required for PGC- $1 \alpha$ induction. Collectively, these data indicate that RIP1 regulates PGC- $1 \alpha$ transcription.

RIP1 mediates Akt signaling, and Akt has been shown to repress PGC- $1 \alpha$ expression. ${ }^{30}$ However, both basal and growth factor-induced Akt activation were not altered in 

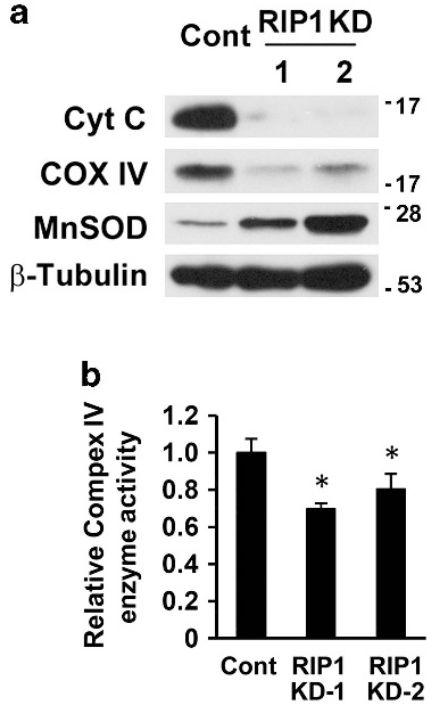
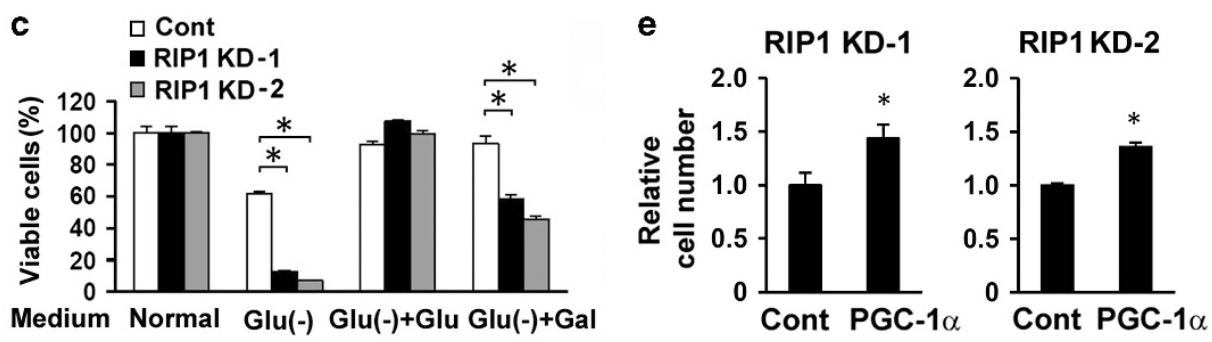

d

RIP1 KD-1

Plasmid Cont PGC-1 $\alpha$

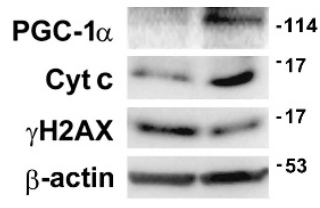

RIP1 KD-2

Cont PGC-1 $\alpha$

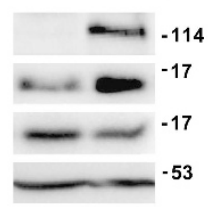

f

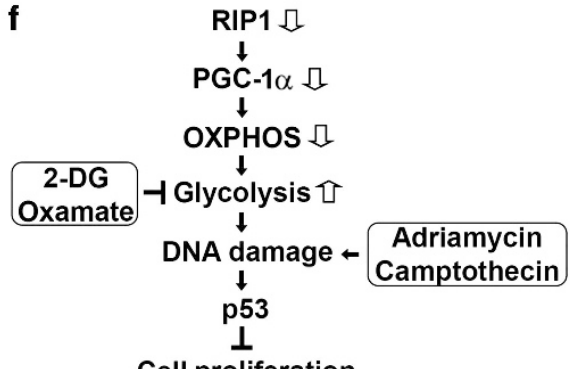

Figure 6 Dysfunction of mitochondrial respiration in RIP1 knockdown cells. (a) Cyt c, COXIV and MnSOD expression in A549 control (Cont) and RIP1 KD cells. $\beta$-Tubulin was probed as a loading control. (b) Mitochondrial electron transfer chain complex IV enzyme activity in A549 control (Cont) and RIP1 KD cells. The values are mean \pm S.D. from triplicate samples. ${ }^{*} P<0.05$ versus control. (c) Survival of A549 control (cont) and RIP1 KD cells cultured in normal, glucose-free, or glucose-free media supplemented with $10 \mathrm{mM}$ glucose (Glu) or galactose (Gal). The values are mean \pm S.D. from triplicate samples. ${ }^{*} P<0.05$. (d, e) Ectopic expression of PGC-1 $\alpha$, cyt c and $\gamma H 2 A X$ in $A 549$ RIP1 KD cells transfected with control (Cont) or PGC-1 $\alpha$ expressing plasmid for $48 \mathrm{~h}$. $\beta$-actin was probed as loading control (d). Cell proliferation was determined 4 days posttransfection (e). The values are mean \pm S.D. from triplicate samples. ${ }^{*} P<0.05$ versus control. (f) Summary of main findings in this work. See the text for detailed discussion

RIP1 knockdown cells (data not shown). p53 has also been shown to suppress PGC- $1 \alpha$ expression, ${ }^{31}$ and p53 was elevated in RIP1 knockdown cells (Figure 1a and Supplementary Figure 1a). However, suppression of p53 in RIP1 knockdown cells did not elevate the expression of PGC-1 $\alpha$ (Supplementary Figure $5 \mathrm{c}$ ). These results demonstrate that RIP1 knockdown-mediated PGC- $1 \alpha$ suppression does not involve p53 or Akt.

Downregulation of PGC-1 $\alpha$ impairs mitochondrial OXPHOS in RIP1 knockdown cells. OXPHOS dysfunction is known to lead to compensatory glycolysis, and inhibition of mitochondrial respiration enhances glycolysis. ${ }^{25}$ Thus, we sought to determine whether downregulation of PGC- $1 \alpha$ impaired OXPHOS in RIP1 knockdown cells. Consistent with the reduced expression of PGC-1 $\alpha$, the expression of the mitochondrial electron transfer chain components cytochrome c (cyt c) and cytochrome c oxidase IV (COX IV), both PGC-1 $\alpha$ target genes, ${ }^{32}$ were decreased in RIP1 knockdown cells (Figure 6a and Supplementary Figure 6a). Microarray data showed that RIP1 knockdown caused a massive expression reduction in components in all the complexes of the electron transport chain (Supplementary Table 1). Many of these genes are targets of the nuclear respiratory factor (NRF)-1/2 or estrogen-related receptor (ERR) $\alpha / \gamma$, for which PGC- $1 \alpha$ is a co-activator. ${ }^{33-35}$ Accordingly, the complex IV enzyme activity was significantly lower in RIP1 knockdown cells (Figure $6 \mathrm{~b}$ and Supplementary Figure 6b). Both mitochondrial mass and DNA content in RIP1 knockdown cells were comparable to that in control cells (Supplementary Figures $6 \mathrm{c}$ and $6 \mathrm{~d}$ ). When cells were cultured in low glucose (glucose supplied only in $10 \%$ serum), the majority of control cells, but few RIP1 knockdown cells, survived (Figure $6 c$ and Supplementary Figure 6e). Replenishing the medium with glucose supported the growth of both control and RIP1 knockdown cells. However, the addition of galactose, which forces cells to rely on mitochondrial OXPHOS for energy production, ${ }^{36}$ did not rescue RIP1 knockdown cells to those levels observed in controls (Figure $6 \mathrm{c}$ and Supplementary Figure 6e). Thus, RIP1 knockdown cells were unable to efficiently use galactose to sustain cell growth when compared with control cells, indicating reduced OXPHOS function. ${ }^{36}$ Finally, partial restoration of PGC-1 $\alpha$ in RIP1 knockdown cells increased the expression of cyt $\mathrm{c}$, reduced $\gamma \mathrm{H} 2 \mathrm{AX}$ and promoted cell proliferation (Figures $6 \mathrm{~d}$ and $\mathrm{e}$ ), suggesting that PGC-1 $\alpha$ suppression mediated the mitochondrial OXPHO defect in these cells.

\section{Discussion}

This study provides evidence that RIP1 regulates glucose metabolism. Knockdown of RIP1 resulted in OXPHOS defect and excessive glycolysis, leading to spontaneous DNA damage and suppression of cell proliferation mediated by p53. We identified PGC- $1 \alpha$ as a key mediator in the defect of mitochondrial OXPHOS. Furthermore, excessive glycolysis rendered cells more vulnerable to cytotoxicity induced by genotoxic agents and glycolysis inhibitors. Our data suggest that, although the Warburg effect favors cancer cell proliferation, maintenance of glycolysis in an optimal range by RIP1 is pivotal for cancer cell energy homeostasis and for maintaining DNA integrity, and intervention in this pathway may be exploited for use in anticancer therapy (Figure 6f). 
PGC- $1 \alpha$ controls mitochondrial biogenesis and metabolism and is involved in diverse diseases including diabetes, heart failure, aging and cancer. ${ }^{37,38}$ Here we show that RIP1 positively regulates $\mathrm{PGC}-1 \alpha$ transcription. Although there was no loss of mitochondrial mass or DNA content in RIP1 knockdown cells, there was a marked reduction in components of the electron transfer chain including cyt $c$ and COX IV, leading to compromised enzyme activity that may account for the defect in mitochondrial OXPHOS. Similar findings in PGC- $1 \alpha$ expression and mitochondrial function were reported recently in vivo. ${ }^{31}$ RIP1 appears to be necessary but insufficient to maintain the level of PGC- $1 \alpha$, as seen upon glucose starvation, PGC- $1 \alpha$ decreased in the presence of RIP1. Upon lethal stimulation, cellular energy status is the key for a cell's decision to proceed towards the processes of either apoptosis or necroptosis. Therefore, it remains to be determined whether PGC-1 $\alpha$ participates in the RIP1-mediated cell death decision. The mechanism by which RIP1 controls PGC$1 \alpha$ expression is still unclear. RIP1 mediates pathways that have been shown to control the transcription of PGC- $1 \alpha^{39}$ Alternatively, as a nuclear protein, ${ }^{40}$ RIP1 may act as a co-activator for PGC-1 $\alpha$ transcription.

Although aerobic glycolysis serves cancer cells in proliferation and survival through maintenance of biosynthesis and redox homeostasis, excessive glycolysis may be harmful to cancer cells. For example, oncogene hyperactivationenhanced aerobic glycolysis was associated with endoplasmic reticulum stress and demise in murine $\mathrm{Ba} / \mathrm{F} 3$ pro-B-cells. ${ }^{41}$ Currently, it is unclear whether there is a beneficial threshold for glycolysis in cancer cells. We demonstrated that RIP1 knockdown in lung cancer cells impaired mitochondrial OXPHOS, forcing the cells to rely heavily on glycolysis for energy supply. Meanwhile, excessive glycolysis resulted in DNA damage-mediated p53 activation and p53-dependent proliferation inhibition. Thus, in cancer cells with an established energetic homeostasis favoring a glycolytic phenotype, shifting toward increased glycolysis may not necessarily endorse but rather could suppress proliferation.

Cancer cells exhibit inherent genomic instability that is largely attributed to increased DNA damaging factors such as ROS and defects in DNA repair. Given that metabolic transformation is a hallmark of cancer cells, the contribution of aerobic glycolysis to genomic instability in cancer cells deserves further investigation. The glycolysis inhibitor 2-DG has long been known to reduce oxidative DNA damage, ${ }^{42}$ and recently it was shown to inhibit ATM activation and $\gamma \mathrm{H} 2 \mathrm{AX}$ in human lymphoblastoid cells, presumably by reducing ROS production. ${ }^{43}$ However, 2-DG was also reported to increase radiation-induced DNA damage. ${ }^{44,45}$ Further, aerobic glycolysis is believed to help cancer cells manage elevated oxidative stress level. ${ }^{5}$ In our studies, basal ROS production was not altered in RIP1 knockdown cells. However, excessive glycolysis seemed to perturb $\mathrm{NAD}^{+}$metabolism, which is an essential cofactor for DNA repair enzymes such as the Sirtuin and PARP family members. ${ }^{46}$ Therefore, excessive glycolysis may contribute to genomic instability in cancer cells and maintenance of glycolysis in an optimal range could be important for DNA repair capacity.

An important question to answer is whether downregulation of RIP1 can be exploited in cancer therapy. It has been documented that downregulation of RIP1 sensitizes cancer cells to tumor necrosis factor (TNF) and TNF-related apoptosis-inducing ligand (TRAIL). ${ }^{47,48}$ These effects were mainly attributed to a survival disadvantage because RIP1 downregulation blunts therapeutic-induced NF- $\kappa \mathrm{B}$ activation. ${ }^{49}$ However, the role of RIP1 in cancer therapy is complicated by evidence demonstrating the pivotal role of RIP1 in both apoptosis and necroptosis. ${ }^{50}$ Thus, the consequences of RIP1 knockdown combined with other treatments could be cell type-specific and context-dependent, and could also depend on the type and dose of the treatment. ${ }^{51}$ Of note, Although genotoxic anticancer drugs primarily induce various types of DNA damage, they also alter other cellular activities including metabolism. ${ }^{52}$ Here we show that RIP1 knockdown renders cancer cells with wild-type p53 more vulnerable to both DNA damaging anticancer agents and glycolysis inhibitors, supporting the targeting of RIP1 as an approach to use in combined cancer therapy. Remarkably, because excessive glycolysis may restrain cancer cell proliferation, limited glycolysis inhibition may be detrimental. Thus, it would be critical to monitor RIP1 expression and the effectiveness of glycolysis suppression during therapy targeting glycolysis.

In summary, our results show a function for RIP1 in cell metabolism through the regulation of PGC- $1 \alpha$ expression. Although the Warburg effect favors cancer cell proliferation, maintenance of glycolysis in a suitable range by RIP1 is pivotal for cancer cell energy homeostasis and for maintaining DNA integrity, and intervention in this pathway could be exploited for use in anticancer therapy. Given the broad function of PGC-1 $\alpha$ in mitochondrial metabolism and in diverse diseases, it is of great interest to investigate the role of RIP1 in related disorders.

\section{Materials and Methods}

Reagents. ATM/ATR (Ataxia telangiectasia mutated/ataxia telangiectasia and Rad3-related) kinase inhibitor CGK733 was from Calbiochem (La Jolla, CA, USA). Benzo[a]pyrene diol epoxide (BPDE) was purchased from $\mathrm{NCl}$ Chemical Carcinogen Reference Standards Repository. All other chemicals were from Sigma (St. Louis, MO, USA). The antibodies used were anti-MDM2, anti-p21(BD Biosciences, San Jose, CA, USA), anti-cytochrome c (BioLegend, San Diego, CA, USA), anti-phospho-CHK1, anti-phospho-CHK2, anti-cytochrome c oxidase IV, anti-phospho-H2AX (serine 139, $\gamma \mathrm{H} 2 \mathrm{AX}$; rabbit), anti-p53 (rabbit; Cell Signaling, Beverly, MA, USA), anti-phospho-ATM (Epitomics, Burlingame, CA, USA), antip53 (mouse), anti-Xpress (Omni-probe), anti-GAPDH (glyceraldehyde phosphate dehydrogenase; Santa Cruz, Santa Cruz, CA, USA), anti- $\beta$-actin, anti- $\beta$-tubulin (Sigma); anti-PGC- $1 \alpha$ and anti- $\gamma \mathrm{H} 2 \mathrm{AX}$ (mouse) (Millipore, Billerica, MA, USA).

Cell culture. Lung cancer cells line A549, H460, H23, H2009 and H1299 were from American Typical Culture Center (ATCC, Manassas, VA, USA) and were maintained in RPMl 1640 supplemented with $10 \%$ fetal bovine serum (FBS), $2 \mathrm{mM}$ L-glutamine and antibiotics (100 $\mu \mathrm{g} / \mathrm{ml}$ of penicillin and $100 \mathrm{U} / \mathrm{ml}$ of streptomycin). Wild-type and RIP1 knockout (RIP1 ${ }^{-1}$ ) mouse embryonic fibroblasts (MEFs) have been described previously. ${ }^{53}$ MEFs and HEK293 cells were cultured in DMEM containing high glucose, 10\% FBS and antibiotics. RPMI 1640 Medium without glucose was purchased from MP Biomedicals (Solon, OH, USA).

Establishment of stable cells lines. Lentiviral vectors with short hairpin RNAs (shRNA) against RIP1 and control vectors were purchased from Open Biosystems (Lafayette, CO, USA). Viruses were produced and packaged in HEK293T cells according to the manufacturer's instructions. A pLKO.1 backbone harboring a shRNA sequence of $5^{\prime}$-CCGGAGGTCATGTTCTTTCAGCTTACTC GAGTAAGCTGAAAGAACATGACCTTTTTT-3' (RHS3979-9569092) was used to 
establish A549, H23, H2009 and H1299 RIP1 knockdown cell lines. H460 RIP1 knockdown cell lines were created with a pGIPZ vector with a shRNA sequence of 5'-TGCTGTTGACAGTGAGCGCGCAGTTGATAATGTGCATAAATAGTGAAG CCACAGATGTATTTATGCACATTATCAACTGCTTGCCTACTGCCTCGGA-3'

(RHS4430-98902904). Cells were infected with viruses and selected with $5 \mu \mathrm{g} / \mathrm{ml}$ of puromycin. Positive clones were expanded and maintained in medium with $1 \mu \mathrm{g} / \mathrm{ml}$ of puromycin.

Cell proliferation and viability assay. Cells were seeded in triplicate at a density of $5 \times 10^{4} /$ well and after staining with trypan-blue were counted every day for 3 days. In some experiments, cells were seeded in triplicate at a density of $2.5 \times 10^{4} /$ well. The next day and thereafter, cells were incubated with $20 \mu \mathrm{g} / \mathrm{ml}$ MTT ((3-(4,5-Dimethylthiazol-2-yl)-2,5-diphenyltetrazolium bromide) for $3 \mathrm{~h}$. MTT was then dissolved in DMSO and read at OD $570 \mathrm{~nm}$. The results were expressed as relative cell number against the corresponding readings from the cells on day 1 set to 1 . Cell viability was detected with MTT and expressed as percentage with control set to 100 .

Colony formation assay. Cells $\left(1 \times 10^{4} /\right.$ well $)$ were seeded in $0.6 \%$ soft agar in triplicate. After 10 days, four random fields of cell colonies from each well were photographed, counted and expressed as colonies per field.

Western blot. Cell lysate was prepared with M2 buffer $(20 \mathrm{mM}$ Tris- $\mathrm{HCl}, \mathrm{pH}$ 7.6, $0.5 \% \mathrm{NP}-40,250 \mathrm{mM} \mathrm{NaCl}, 3 \mathrm{mM}$ ethylenediaminetetraacetic acid, $3 \mathrm{mM}$ ethyleneglycol-bis(aminoethylether)-tetraacetic acid, $2 \mathrm{mM}$ dithiothreitol, $0.5 \mathrm{mM}$ phenylmethylsulfonyl fluoride, $20 \mathrm{mM} \beta$-glycerophosphate, $1 \mathrm{mM}$ sodium vanadate and $1 \mu \mathrm{g} / \mathrm{ml}$ leupeptin). Protein concentration was determined with Bio-Rad Bradford assay reagent. Protein samples were separated with SDS-PAGE and transferred to polyvinylidene fluoride membrane. The membrane was blocked with $5 \%$ nonfat milk in PBS with $0.5 \%$ Tween-20, incubated with primary and second antibodies, and visualized with enhanced chemiluminescence reagent (Millipore). The approximate positions $(\mathrm{kDa})$ of prestained protein standards (Bio-Rad, Hercules, CA, USA) were indicated on the right of the blots. In some experiments, the band density was quantified with $\mathrm{NIH}$ ImageJ software ( $\mathrm{NIH}$, Bethesda, MD, USA), normalized to corresponding loading control, and then the fold change was shown.

Transfection, RNA interference and reporter assay. SmartPool siRNAs were purchased from Thermo Scientific (Waltham, MA, USA) and transfections $(10 \mathrm{nM})$ were performed with INTERFERin (Polyplus Transfection, New York, NY, USA). Transient plasmid transfection was carried out using Fugene HD (Promega, Madison, WI, USA). Xpress-tagged pcDNA-RIP1 (Xp-RIP1) and its death domain (DD) deletion $(\triangle D D)$ and kinase death $(K 45 A)$ mutants and NF- $\kappa B$ luciferase reporter plasmid have been previously described. ${ }^{53}$ pcDNA-PGC- $1 \alpha$ plasmid was purchased from Addgene (Cambridge, MA, USA) and was deposited by Dr. Bruce M. Spiegelman (Harvard Medical School). ${ }^{54}$ PGC-1 $\alpha$ promoter luciferase construct $(-992$ to $+90 \mathrm{bp}$ on pGL3 vector) was a kind gift from Dr. Akiyoshi Fukamizu (University of Tsukuba, Japan). ${ }^{55}$ For RIP1 overexpression and reporter assay in HEK293 cells, PGC- $1 \alpha$ promoter construct was cotransfected with various amounts of pcDNA-RIP1 together with a $\beta$-galactosidase expressing vector to monitor transfection efficiency. The amounts of plasmids were kept constant with addition of pcDNA3.1 control vector. Eighteen hours post tranfection, cell lysate was prepared for luciferase and $\beta$-galactosidase activity assays using reagents from Promega (Fitchburg, WI, USA). For RIP1 knockdown, reporter assay was carried out $24 \mathrm{~h}$ after transfection of $\mathrm{PGC}-1 \alpha$ promoter construct. Luciferase readings were normalized to that of $\beta$-galactosidase and results were expressed as relative activity against control.

RNA extraction, reverse transcription and polymerase chain reaction. Total RNA was isolated with RNeasy kit (Qiagen, Valencia, CA, USA) or Trizol reagent (Invitrogen, Carlsbad, CA, USA). CDNA was synthesized using a reverse transcription kit (Promega). The PCR conditions for PGC- $1 \alpha$ and PGC- $1 \beta$ were $95^{\circ} \mathrm{C}, 40 \mathrm{~s}, 55^{\circ} \mathrm{C}, 40 \mathrm{~s}, 72^{\circ} \mathrm{C} 40 \mathrm{~s}$ for 32 cycles. Identical conditions with 22 cycles were used for amplifying $\beta$-actin as an internal control. The products were loaded on a $2.5 \%$ agarose gel with $0.5 \mu \mathrm{g} / \mathrm{ml}$ ethidium bromide and visualized under UV light and photographed. The primers used were PGC-1 $\alpha$ : forward: 5'-TTCCTTTCTCTCGCCCAACACGAT; reverse: AAGCAAGCATCCGACAGGACAAAC-3'; PGC-1 $\beta$ : forward: $5^{\prime}$-AGTCTGCTCTGGAATTCACACCCA-3'; reverse: 5'-AGGCTGGCTACAGACACCTTCTTT-3'; $\beta$-actin: forward: $5^{\prime}$-CCAGCCTTCC TTCCTGGGCAT-3'; Reverse: 5'-AGGAGCAATGATCTTGATCTTCATT-3'.
Immunofluorescence. Cells were seeded on cover slide and fixed with cold methanol. Subsequently, cells were permeabilized with $0.5 \%$ Triton X-100 in PBS for $5 \mathrm{~min}$, blocked with $5 \%$ normal donkey serum for $2 \mathrm{~h}$, followed by incubation with rabbit anti- $\gamma \mathrm{H} 2 \mathrm{AX}(1: 200)$ overnight at $4{ }^{\circ} \mathrm{C}$. The slide was further incubated with Alexa Fluor 680-labeled donkey anti-rabbit secondary antibody (Invitrogen; $1: 500$ ) for $2 \mathrm{~h}$, and then mounted with Fluormount-G (SouthernBiotech, Birmingham, AL, USA) with DAPI (4', 6-diamidino-2-phenylindole) to stain nuclei. Images of the cells were captured using a fluorescence microscope (Carl Zeiss, Germany).

Lactate production. Cells were seeded in triplicate overnight and then incubated with fresh medium containing $1 \%$ FBS for $24 \mathrm{~h}$. Lactate concentration in culture medium was determined using lactate assay kit from BioVision (BioVision, Milpitas, CA, USA) and normalized to total cellular protein.

Lactate dehydrogenase activity assay. Cellular LDH activity was determined using CytoTox 96 Non-Radioactive Cytotoxicity Assay kit from Promega. Cells were lysed in M2 buffer, total protein concentrations were measured and then equal amounts of lysates was used for the reaction. Results were expressed as relative activity against control.

Glucose consumption. Equal numbers of cells were seeded in triplicate overnight and then incubated with fresh medium for $24 \mathrm{~h}$. Glucose concentration in culture medium was measured with an assay kit from BioVision. Glucose consumption was calculated by subtraction of glucose amount in medium with cells from that of control without cells in the same plate and then normalized to total cellular proteins.

ATP production. Equal number of cells were seeded in triplicate overnight and then incubated with fresh medium for $24 \mathrm{~h}$. ATP was measured in cell lysates with equal amounts of protein with an ATP assay kit from BioVision.

Cell fractionation and detection of cellular NAD ${ }^{+}$. Cells were first suspended in hypotonic buffer (10 mM HEPES, pH 7.9, $1.5 \mathrm{mM} \mathrm{MgCl}_{2}, 10 \mathrm{mM}$ $\mathrm{KCl}, 0.5 \mathrm{mM}$ DTT and $0.5 \mathrm{mM}$ PMSF) before addition of detergent (NP-40) to a final concentration of $0.5 \%$ followed by homogenization. Nuclei were precipitated by centrifugation at $300 \times g$ for $10 \mathrm{~min}$ at $4{ }^{\circ} \mathrm{C}$. The supernatant was reserved as cytoplasmic fraction. Cytosolic fraction was obtained by further centrifuging the cytoplasmic fraction at $14000 \times g$ for 20 min at $4{ }^{\circ} \mathrm{C}$. Total NAD and NADH were determined with NAD/NADH quantification kit from ScienCell Research Laboratories (Carlsbad, CA, USA) or BioVision according to the manufacture's instructions. Total cell lysates were prepared with the extract buffer provided with the kit. For measurement of $\mathrm{NADH}$, cell lysate was heated at $60^{\circ} \mathrm{C}$ for $30 \mathrm{~min}$ to decompose $\mathrm{NAD}^{+}$. NAD ${ }^{+}$levels were calculated by subtracting NADH concentration from that of total NAD. Results were normalized to protein concentrations and expressed as relative levels against control.

Detection of reactive oxygen species. Dichlorodihydrofluorescein diacetate (CM- $\mathrm{H}_{2} \mathrm{DCFDA}, 5 \mu \mathrm{M}$; Invitrogen) was added into the culture medium $30 \mathrm{~min}$ before collecting cells. The fluorescence intensity was detected using a fluorescence plate reader and normalized to total cellular proteins.

Mitochondrial mass. Cells were stained with $50 \mathrm{nM}$ of MitoTracker (Invitrogen) for $30 \mathrm{~min}$ in cell culture incubator. Cells were then collected by trypsinization, fixed in $3.7 \%$ formaldehyde for $15 \mathrm{~min}$ at $37^{\circ} \mathrm{C}$ and subjected to flow cytometry analysis (FACSCalibur, BD Biosciences).

Mitochondrial DNA content. Mitochondrial DNA content was determined with quantitative real-time PCR (qPCR) using the method and primers described by Karamanlidis et al. ${ }^{56}$ Total DNA was isolated by proteinase $\mathrm{K}$ digestion and ethanol precipitation. GPCR was performed with the ABI PRISM 7900HT. The ratio of cytochrome $\mathrm{C}$ oxidase I (COXI) to $18 \mathrm{~S}$ was reported, although similar results were obtained with $16 \mathrm{~S}$ to $18 \mathrm{~S}$ ratios (data not shown).

Mitochondrial complex IV enzyme activity. Cell extract was prepared and enzyme activity determined using an assay kit (ab109909) from Abcam (Cambridge, MA, USA) according to the manufacturer's protocol. The amount of lysate used was $15 \mu \mathrm{g}$ for $\mathrm{A} 549$ and $30 \mu \mathrm{g}$ for $\mathrm{H} 460$. The results were further expressed as relative level with control as 1 . 
Tumorigenicity assay in nude mice. The animal usage and experimental protocols were approved by the Institutional Animal Care and Use Committee (IACUC) of Lovelace Respiratory Research Institute. Wild-type, control and RIP1 knockdown A549 cells were collected and washed twice with PBS. Aliquots of $1 \times 10^{6}$ cells were suspended in $50 \mu \mathrm{l}$ of PBS mixed with $50 \mu \mathrm{l}$ of Matrigel (BD Biosciences) and injected subcutaneously at the right and left flanks of athymic nude mice (BALB/c nu/nu, 4-6 weeks old). Tumors were measured using a caliper, and tumor volumes were calculated using the following formula: tumor volume $=1 / 2$ length $\times$ width $^{2}$.

Gene expression array. Total RNA was extracted with Trizol reagent. cDNA array assay was performed with Affimatrix GeneChip HT HG-U133+, and the results were analyzed at the Keck-UNM Genomics Resource (KUGR), University of New Mexico.

Statistics. Quantitative data were expressed as mean \pm S.D. (Standard deviation). Comparison of two means was carried out using two-tailed Student's t-test with Prism 5 software (GraphPad Software, La Jolla, CA, USA). A P-value $<0.05$ was considered statistically significant.

\section{Conflict of Interest}

The authors declare no conflict of interest.

Acknowledgements. We thank Dr. Akiyoshi Fukamizu (University of Tsukuba, Japan) for providing the human PGC-1 promoter luciferase construct and Dr. Bruce M. Spiegelman (Harvard Medical School) for the deposit of PGC-1 expressing plasmid to Addgene. We are grateful to Tamara Howard, MS, Department of Cell Biology and Physiology, University of New Mexico, for help in experiments. This work was partially supported by NIH grants R01ES017328 (Y.L.) and R03CA167727 (W.C.), and a grant (DE-FG02-09ER64783) from Low Dose Radiation Program, U.S. Department of Energy (Y.L).

1. Warburg O. On the origin of cancer cells. Science 1956; 123: 309-314.

2. Seyfried TN, Shelton LM. Cancer as a metabolic disease. Nutr Metab 2010; 7: 7 .

3. Zhang WC, Shyh-Chang N, Yang H, Rai A, Umashankar S, Ma S et al. Glycine decarboxylase activity drives non-small cell lung cancer tumor-initiating cells and tumorigenesis. Cell 2012; 148: 259-272.

4. Sebastian C, Zwaans BM, Silberman DM, Gymrek M, Goren A, Zhong L et al. The histone deacetylase SIRT6 is a tumor suppressor that controls cancer metabolism. Cell 2012; 151 $1185-1199$.

5. Cairns RA, Harris IS, Mak TW. Regulation of cancer cell metabolism. Nat Rev 2011; 11: 85-95

6. Ward PS, Thompson CB. Metabolic reprogramming: a cancer hallmark even warburg did not anticipate. Cancer Cell 2012; 21: 297-308.

7. Levine AJ, Puzio-Kuter AM. The control of the metabolic switch in cancers by oncogenes and tumor suppressor genes. Science 2010; 330: 1340-1344.

8. Dang CV. Links between metabolism and cancer. Gene Dev 2012; 26: 877-890.

9. Vandenabeele P, Galluzzi L, Vanden Berghe T, Kroemer G. Molecular mechanisms of necroptosis: an ordered cellular explosion. Nat Rev Mol Cell Biol 2010; 11: 700-714.

10. Park S, Ramnarain DB, Hatanpaa KJ, Mickey BE, Saha D, Paulmurugan R et al. The death domain-containing kinase RIP1 regulates p27(Kip1) levels through the PI3K-Akt-forkhead pathway. EMBO Rep 2008; 9: 766-773.

11. Lin $Y$, Yang $Q$, Wang $X$, Liu ZG. The essential role of the death domain kinase receptorinteracting protein in insulin growth factor--Induced c-Jun $\mathrm{N}$-terminal kinase activation. J Biol Chem 2006; 281: 23525-23532.

12. Declercq W, Vanden Berghe T, Vandenabeele P. RIP kinases at the crossroads of cell death and survival. Cell 2009; 138: 229-232.

13. Temkin V, Huang $Q$, Liu H, Osada H, Pope RM. Inhibition of ADP/ATP exchange in receptor-interacting protein-mediated necrosis. Mol Cell Biol 2006; 26: 2215-2225.

14. Kasof GM, Prosser JC, Liu D, Lorenzi MV, Gomes BC. The RIP-like kinase, RIP3, induces apoptosis and NF-kappaB nuclear translocation and localizes to mitochondria. FEBS Lett 2000; 473: 285-291.

15. Wang $Z$, Jiang $H$, Chen S, Du F, Wang $X$. The mitochondrial phosphatase PGAM5 functions at the convergence point of multiple necrotic death pathways. Cell 2012; 148 : 228-243.

16. Zhang DW, Shao J, Lin J, Zhang N, Lu BJ, Lin SC et al. RIP3, an energy metabolism regulator that switches TNF-induced cell death from apoptosis to necrosis. Science 2009; 325: 332-336.

17. Park S, Hatanpaa KJ, Xie Y, Mickey BE, Madden CJ, Raisanen JM et al. The receptor interacting protein 1 inhibits p53 induction through NF-kappaB activation and confers worse prognosis in glioblastoma. Cancer Res 2009; 69: 2809-2816.
18. Roth J, Koch $\mathrm{P}$, Contente A, Dobbelstein M. Tumor-derived mutations within the DNA-binding domain of p53 that phenotypically resemble the deletion of the proline-rich domain. Oncogene 2000; 19: 1834-1842.

19. Reinhardt HC, Schumacher B. The p53 network: cellular and systemic DNA damage responses in aging and cancer. Trends Genet 2012; 28: 128-136.

20. Burma S, Chen BP, Murphy M, Kurimasa A, Chen DJ. ATM phosphorylates histone H2AX in response to DNA double-strand breaks. J Biol Chem 2001; 276: 42462-42467.

21. Mah LJ, El-Osta A, Karagiannis TC. gammaH2AX: a sensitive molecular marker of DNA damage and repair. Leukemia 2010; 24: 679-686.

22. Sarkaria JN, Busby EC, Tibbetts RS, Roos P, Taya Y, Karnitz LM et al. Inhibition of ATM and ATR kinase activities by the radiosensitizing agent, caffeine. Cancer Res 1999; 59: 4375-4382.

23. Ciccia A, Elledge SJ. The DNA damage response: making it safe to play with knives. Mol Cell 2010; 40: 179-204.

24. Wang $L$, Du F, Wang $X$. TNF-alpha induces two distinct caspase-8 activation pathways. Cell 2008; 133: 693-703.

25. Wu M, Neilson A, Swift AL, Moran R, Tamagnine J, Parslow D et al. Multiparameter metabolic analysis reveals a close link between attenuated mitochondrial bioenergetic function and enhanced glycolysis dependency in human tumor cells. Am J Physiol Cell Physiol 2007; 292: C125-C136.

26. Surjana D, Halliday GM, Damian DL. Role of nicotinamide in DNA damage, mutagenesis, and DNA repair. J Nucleic Acids 2010; 2010: 157591

27. Belenky P, Bogan KL, Brenner C. NAD + metabolism in health and disease. Trends Biochem Sci 2007; 32: 12-19.

28. Lim JH, Lee YM, Chun YS, Chen J, Kim JE, Park JW. Sirtuin 1 modulates cellular responses to hypoxia by deacetylating hypoxia-inducible factor 1alpha. Mol Cell 2010; 38: 864-878.

29. DeBerardinis RJ, Lum JJ, Hatzivassiliou G, Thompson CB. The biology of cancer: metabolic reprogramming fuels cell growth and proliferation. Cell Metab 2008; 7: 11-20.

30. Borniquel S, Garcia-Quintans N, Valle I, Olmos Y, Wild B, Martinez-Granero F et al. Inactivation of Foxo3a and subsequent downregulation of PGC-1 alpha mediate nitric oxide-induced endothelial cell migration. Mol Cell Biol 2010; 30: 4035-4044.

31. Sahin E, Colla S, Liesa M, Moslehi J, Muller FL, Guo M et al. Telomere dysfunction induces metabolic and mitochondrial compromise. Nature 2011; 470: 359-365.

32. Wu Z, Puigserver P, Andersson U, Zhang C, Adelmant G, Mootha V et al. Mechanisms controlling mitochondrial biogenesis and respiration through the thermogenic coactivator PGC-1. Cell 1999; 98: 115-124.

33. Lin J, Handschin C, Spiegelman BM. Metabolic control through the PGC-1 family of transcription coactivators. Cell Metab 2005; 1: 361-370.

34. Giguere V. Transcriptional control of energy homeostasis by the estrogen-related receptors. Endocrine Rev 2008; 29: 677-696.

35. Kelly DP, Scarpulla RC. Transcriptional regulatory circuits controlling mitochondrial biogenesis and function. Gene Dev 2004; 18: 357-368.

36. Robinson BH, Petrova-Benedict R, Buncic JR, Wallace DC. Nonviability of cells with oxidative defects in galactose medium: a screening test for affected patient fibroblasts. Biochem Med Metab Biol 1992; 48: 122-126.

37. Handschin C. The biology of PGC-1alpha and its therapeutic potential. Trends Pharmaco Sci 2009; 30: 322-329.

38. Girnun GD. The diverse role of the PPARgamma coactivator 1 family of transcriptional coactivators in cancer. Semin Cell Dev Biol 2012; 23: 381-388.

39. Fernandez-Marcos PJ, Auwerx J. Regulation of PGC-1alpha, a nodal regulator of mitochondrial biogenesis. Am J Clin Nutr 2011; 93: 884S-890S.

40. Janssens S, Tinel A, Lippens S, Tschopp J. PIDD mediates NF-kappaB activation in response to DNA damage. Cell 2005; 123: 1079-1092.

41. Dengler MA, Staiger AM, Gutekunst M, Hofmann U, Doszczak M, Scheurich P et al. Oncogenic stress induced by acute hyper-activation of Bcr-Abl leads to cell death upon induction of excessive aerobic glycolysis. PLoS One 2011; 6: e25139.

42. Birnboim HC, Kanabus-Kaminska M. The production of DNA strand breaks in human leukocytes by superoxide anion may involve a metabolic process. Proc Natl Acad Sci USA 1985; 82: 6820-6824

43. Tanaka T, Kurose A, Halicka HD, Traganos F, Darzynkiewicz Z. 2-deoxy-D-glucose reduces the level of constitutive activation of ATM and phosphorylation of histone H2AX. Cell Cycle 2006; 5: 878-882

44. Jain VK, Kalia VK, Sharma R, Maharajan V, Menon M. Effects of 2-deoxy-D-glucose on glycolysis, proliferation kinetics and radiation response of human cancer cells. Int $J$ Radiat Oncol Biol Phys 1985; 11: 943-950.

45. Dwarkanath BS, Zolzer F, Chandana S, Bauch T, Adhikari JS, Muller WU et al. Heterogeneity in 2-deoxy-D-glucose-induced modifications in energetics and radiation responses of human tumor cell lines. Int J Radiat Oncol Biol Phys 2001; 50: 1051-1061.

46. Chiarugi A, Dolle C, Felici R, Ziegler M. The NAD metabolome-a key determinant of cancer cell biology. Nat Rev 2012; 12: 741-752.

47. Wang $X$, Ju W, Renouard J, Aden J, Belinsky SA, Lin Y. 17-allylamino-17demethoxygeldanamycin synergistically potentiates tumor necrosis factor-induced lung cancer cell death by blocking the nuclear factor-kappaB pathway. Cancer Res 2006; 66: $1089-1095$

48. Wang P, Zhang J, Bellail A, Jiang W, Hugh J, Kneteman NM et al. Inhibition of RIP and c-FLIP enhances TRAIL-induced apoptosis in pancreatic cancer cells. Cell signalling 2007; 19: $2237-2246$. 
49. Hur GM, Lewis J, Yang Q, Lin Y, Nakano H, Nedospasov S et al. The death domain kinase RIP has an essential role in DNA damage-induced NF-kappa B activation. Gene Dev 2003; 17: $873-882$.

50. Vanlangenakker $\mathrm{N}$, Vanden Berghe $\mathrm{T}$, Vandenabeele $\mathrm{P}$. Many stimuli pull the necrotic trigger, an overview. Cell Death Differ 2012; 19: 75-86.

51. Biton S, Ashkenazi A. NEMO and RIP1 control cell fate in response to extensive DNA damage via TNF-alpha feedforward signaling. Cell 2011; 145: 92-103.

52. Zong WX, Ditsworth D, Bauer DE, Wang ZQ, Thompson CB. Alkylating DNA damage stimulates a regulated form of necrotic cell death. Gene Dev 2004; 18: $1272-1282$
53. Lin Y, Devin A, Rodriguez Y, Liu ZG. Cleavage of the death domain kinase RIP by caspase-8 prompts TNF-induced apoptosis. Genes Dev 1999; 13: 2514-2526.

54. Puigserver P, Wu Z, Park CW, Graves R, Wright M, Spiegelman BM. A cold-inducible coactivator of nuclear receptors linked to adaptive thermogenesis. Cell 1998; 92: 829-839.

55. Daitoku H, Yamagata K, Matsuzaki H, Hatta M, Fukamizu A. Regulation of PGC-1 promoter activity by protein kinase $B$ and the forkhead transcription factor FKHR. Diabetes 2003; 52: 642-649.

56. Karamanlidis G, Bautista-Hernandez V, Fynn-Thompson F, Del Nido P, Tian R. Impaired mitochondrial biogenesis precedes heart failure in right ventricular hypertrophy in congenital heart disease. Circ Heart Fail 2011; 4: 707-713.

Supplementary Information accompanies this paper on Cell Death and Differentiation website (http://www.nature.com/cdd) 